\title{
EXPERIMENTAL ANALYSIS AND OPTIMIZATION OF MATERIAL REMOVAL RATE OF ALUMINIUM 6061 IN PLAIN TURNING
}

\author{
Syed Asghar Husain Rizvi ${ }^{1}$ \\ ${ }^{\text {I}}$ Department of Mechanical Engineering, Ambalika Institute of Management and Technology, Lucknow
}

\begin{abstract}
Due to the advancement of technology, the demand of hour is increasing. Metal machining is one of them important aspect in technology advancement. Majority of work performed by the engineers are to find out the optimal level of parameters to obtain the desired quality and to maximize the performance of machining by the use of available resources. Productivity plays a vital role in the analyzing the performance of a machine.

The present experimental research on plain turning studies the process parameters that are affecting the machining performance and its productivity. Taguchi approach is used for the optimization of parameters and performance measures. In the present work, the machining parameters are cutting speed, feed rate and depth of cut, which are optimized for the maximum material removal rate during turning of Aluminium 6061 with HSS tool. Analysis of Variance is also employed to determine the variable affecting the various responses mentioned above.
\end{abstract}

Keywords: Turning, MRR, Aluminium 6061.

\section{INTRODUCTION}

Due to the advancement of technology demand of the hour is increasing. The prime concern in industries is to maintain economic production using the resources in an optimal way. Machining of metals is one of them. Challenges are to maximize the performance of manufacturing by finding out optimal parameters for. In industries, nowadays dimensional accuracy, surface finish and hardness of material are specially focused.

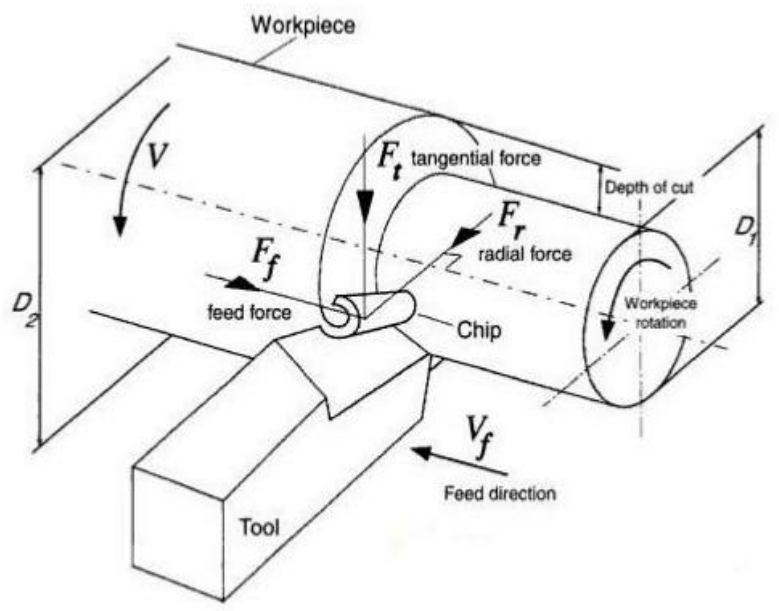

geometry of turning process

Fig 1: Turning Operation

Majority of work performed on turning is to increase the productivity and to improve the surface quality produced by machine. Continuous studies have been performed to improve the material removal efficiency.
S.R. Das et al [1] conducted experiments on Tungsten AISI 4340 steel with Coated Graphite tool inserts. Feed was found to be most significant parameter for the workpiece surface roughness ( $\mathrm{Ra}$ ) with a percent contribution of $52.55 \%$. Cutting speed is found as the second most dominating parameter for $\mathrm{Ra}$ with contribution of $25.85 \%$. Influence of depth of cut is found to be negligible. Jitendra. M. Varma et al [2] conducted experiments on AISI 4340 using solid lubricant with coated carbon tool inserts. It is concluded that the application of solid lubricant in dry machining has proved to be a feasible alternative to cutting fluid. There is a considerable improvement in surface roughness and quality of product produced. Karanam Krishna et al [3] carried an investigation using ANN for material removal rate on Aluminum in turning. This work investigated the influence of the operating parameters like feed rate, depth of cut, clamping length and spindle speed. It was evident that each of these parameters studied contributed to the error in the dimensions of the machined component. Feed rate and depth of cut had more effect on the accuracy than the other parameters. Based on this ANN prediction, the NC program could be corrected before commencing the actual machining operation, thus improving the accuracy of the component at less cost and time.

A.Sathyavathi et al [4] carried a study on different researches conducted. The most of researchers are interested in optimization of machining condition with corresponding surface roughness. In past reviewed found, none of researcher involved for TiBN coated cemented carbide tool. In this paper uncoated carbide tool and PVD (TiBN) coated carbide tool involved for performance of quality of surface and optimization of cutting parameter with aid of DOE and GA. M.M.A. Khan et al [5] carried an investigation to study 
the effects of lubrication quantity on turning AISI 9310 by using vegetable oil-based cutting fluid. They concluded that the continuous chips are produced under both dry and wet condition. Remarkable improvement of tool life span and MRR is obtained by MQL jet using carbide. Higher cutting velocity and feed rate is used as low flank wear is achieved. Thus surface finish is also improved due to reduction in wear and damage at the tool-tip by employing of MQL. M. Venkata Ramana et al [6] carried experiments to study the tool wear while turning titanium alloy. It was concluded that the MQL machining reduces the friction between the toochip interface. ANOVA revealed that contribution of cutting speed is higher followed by the material of tool, depth of cut, feed rate and condition of coolant to minimize tool wear.

Vikas B. Magdum et al [7] carried investigation to evaluate and optimize the machining parameters for turning of EN 8 steel using HSS M2, Carbide and Cermet tools. N.Zeelan Basha et al [8] optimized turning process parameters on Aluminium 6061 using Genetic Algorithm. Optimum surface finish was obtained at maximum cutting speed, minimum feed and minimum depth of cut. Y.B. Kumbhar et al [9] investigated tool life and surface finish optimization of PVD Ti-Al-N/Ti-N multilayer coated carbide tool inserts in semi hard turning of hardened EN-31 alloy steel under dry cutting conditions. Maximum tool life is obtained at low cutting speed, moderate feed rate and depth of cut. Feed was found to be the most influencing factor for tool life. Feed rate was also the most dominating parameter for surface roughness.

\section{EXPERIMENTAL DETAILS}

Work Material: Aluminium 6061

Tool Materail: HSS

Machine Used: ACE Micromatic Apollo CNC Turning Machine.

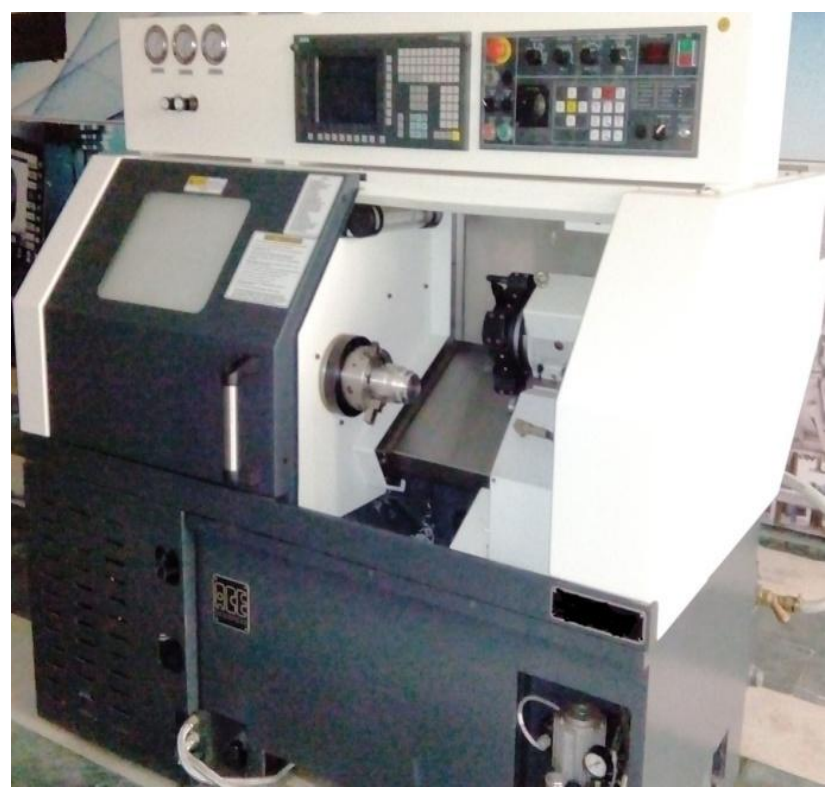

Fig 2. ACE Micromatic Apollo CNC Turning Machine
In the current research Taguchi method is used which is an effective tool to handle responses influenced by multiple parameters. It is a tool for designing of experiments, which is simple, effective, efficient and systematic approach to optimize the results and achieve optimal level of parameters. The current study considers three principal turning parameters that affect its material removal rate which are cutting speed, feed rate and depth of cut. The experiments were performed on the Table 1 summarizes the levels of process parameters set for the experiments set as per Taguchi $\mathrm{L}_{9}$ orthogonal array.

Table 1: The levels of Wire-EDM parameters

\begin{tabular}{|l|l|llll|}
\hline Parameters & Unit & \multicolumn{4}{|l|}{ Levels } \\
\hline Cutting Speed & RPM & 300 & 450 & 600 \\
\hline Feed Rate (f) & $\mathrm{mm} / \mathrm{min}$ & 10 & 15 & 20 \\
\hline Depth of Cut & $\mathrm{Mm}$ & 0.2 & 0.5 & 0.8 \\
\hline
\end{tabular}

ANOVA is performed to identify the process parameters that are statistically significant for the performance measures. ANOVA is used to identify the optimal combination of the process parameters.

\section{RESULTS AND DISCUSSIONS}

\subsection{Material Removal Rate}

The material removal rate is an important performance measure considered while machining as productivity is considered as the most important aspect in industries. The study shows that the material removal rate is dominated by feed, cutting speed and depth of cut and increases with all the three parameters. This is because when the parameters are increased; the time for the length material to be removed reduces which helps in faster removal of work-material from the work piece. Table 2 shows the mean $\mathrm{S} / \mathrm{N}$ ratio for surface roughness.

Table 2 Calculation of mean S/N ratio for Material Removal Rate

$\begin{array}{lrrr} & \text { Cutting } & & \begin{array}{r}\text { Depth } \\ \text { of }\end{array} \\ \text { Level } & \text { Speed } & \text { Feed } & \text { Cut } \\ 1 & 159.3 & 402.1 & 241.3 \\ 2 & 421.9 & 392.0 & 469.4 \\ 3 & 708.5 & 495.5 & 579.0 \\ \text { Delta } & 549.2 & 103.5 & 337.8 \\ \text { Rank } & 1 & 3 & 2\end{array}$

The following Table 3 shows the cutting speed is the most significant factor and has major effect on material removal rate with $62.94 \%$ contribution. Depth of Cut is the second most significant factor for material removal rate with a contribution of $24.75 \%$. Feed Rate has least effect on material removal rate with $2.72 \%$ contribution. 
Table 3 ANOVA for Material Removal Rate

\begin{tabular}{|l|l|l|l|l|}
\hline Source & DOF & SS & $\begin{array}{l}\text { Adj } \\
\text { MS }\end{array}$ & Contribution \\
\hline Speed & 2 & 452787 & 226393 & 62.94 \\
\hline Feed & 2 & 19535 & 9767 & 2.72 \\
\hline $\begin{array}{l}\text { Depth of } \\
\text { Cut }\end{array}$ & 2 & 178125 & 89063 & 24.75 \\
\hline Error & 2 & 69033 & 34516 & 9.59 \\
\hline Total & 8 & 719480 & & $100 \%$ \\
\hline
\end{tabular}

As the cutting speed increases, the material is removed at a faster rate and hence MRR increases. The cutting speed is the most dominating factor for MRR. MRR increases with increase in feed but at a slower pace as compared to that of cutting speed. As we increase the feed, the thickness of work-piece material to be removed increases. This reduces lead time and hence increases material removal rate. In case of depth of cut, as the level of depth of cut is increased, material removal is observed to get increased. Depth of cut is the distance of newly machined surface to the uncut surface. Thus as it is increased, the thickness of workmaterial to be removed increases and hence it will enhance the material removal rate. It can be seen from the three graphs shown above that all the three machining parameters viz. cutting speed, feed per revolution and depth of cut directly affect the MRR and increases with increase in the value of process parameters. Maximum MRR is obtained at $600 \mathrm{RPM}$ speed, $20 \mathrm{~mm}$ feed rate and $0.8 \mathrm{~mm}$ depth of cut.

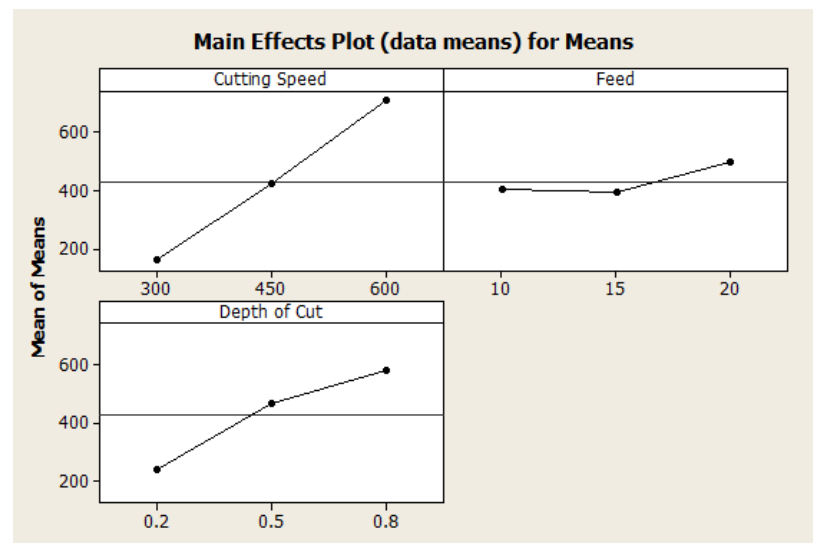

Fig 3: Main Effect Plot For Means For Material Removal Rate

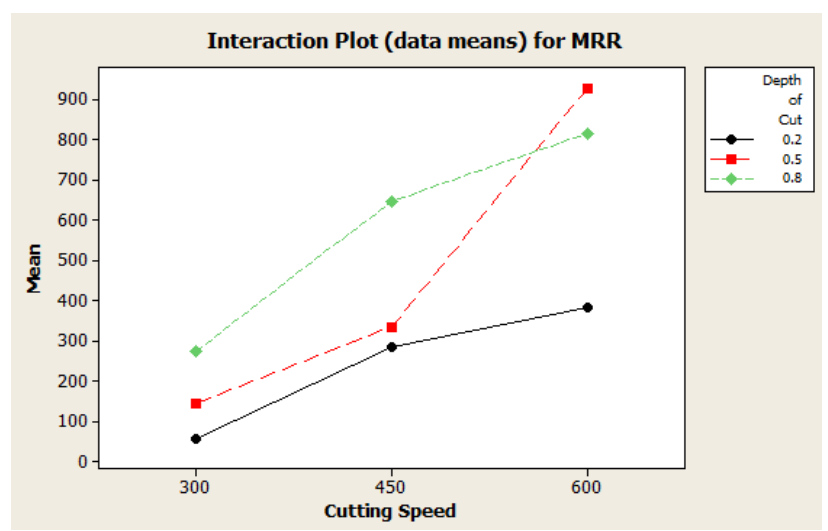

Fig 4: Interaction Plot between MRR and Cutting Speed at different levels of Depth of Cut
The above interaction plot shows that the MRR value increases with the increase of cutting speed at every level of depth of cut. The highest influence of cutting speed with depth of cut is seen at 0.5 depth of cut where the MRR increases gradually.

\section{CONCLUSION}

The experiments conducted on Aluminium 6061 during plain turning to determine the relationship between its parameters and material removal rate have following conclusions:

1. When the Cutting Speed is increased, the time required for the length material to be removed reduces. Thus the MRR will increase with it. The contribution of Cutting Speed is $62.94 \%$.

2. Depth of cut has a similar effect as the cutting speed. The MRR also increases with increase in the level of Depth of cut. The contribution of Depth of cut is $24.75 \%$.

\section{REFERENCES}

[1]. S.R. Das, A. Kumar, D. Dhupal and S.K. Mohapatra "Optimization of Surface Roughness in Hard Turning of AISI 4340 Steel using Coated Carbide Inserts", International Journal of Information and Computation Technology. ISSN 0974-2239 Volume 3, Number 9 (2013), pp. 871-880.

[2]. Jitendra. M. Varma, Chirag. P. Patel; "Parametric Optimization of Hard turning of AISI 4340 Steel by solid lubricant with coated carbide insert", International Journal of Engineering Research and Applications (IJERA) ISSN: 2248-9622 www.ijera.com Vol. 3, Issue 3, May-Jun 2013, pp.1011-1015.

[3]. Karanam Krishna and Ch. Siva Ramakrishna; "Process Parameters Investigation using Ann for Material Removal Rate on Aluminium in Turning", International Journal of Engineering Technology Science and Research IJETSR, ISSN 2394 - 3386, Volume 2 Issue 5, May 2015.

[4]. A.Sathyavathi, M.R.Rajaraman, B.Kumaragurubaran, P.Gopal, "Surface Roughness Optimization Techniques of CNC Turning: A Review", International Journal of Engineering and Advanced Technology (IJEAT) ISSN: 2249 - 8958, Volume-2, Issue-5, June 2013.

[5]. M.M.A. Khana, M.A.H. Mithua, N.R. Dhar, "Effects of minimum quantity lubrication on turning AISI 9310 alloy steel using vegetable oil-based cutting fluid", Journal of Materials Processing Technology 209 (2009) 5573-5583.

[6]. M. Venkata Ramana, G. Krishna Mohan Rao, and D. Hanumantha Rao, "Optimization and Effect of Process Parameters on Tool Wear in Turning of Titanium Alloy under Different Machining Conditions", International Journal of Materials, Mechanics and Manufacturing, Vol. 2, No. 4, November 2014.

[7]. Vikas B. Magdum, Vinayak R. Naik,“ Evaluation and Optimization of Machining Parameter for turning of EN 8 steel", International Journal of Engineering Trends and Technology (IJETT) - Volume4Issue5- May 2013.

[8]. N.Zeelan Basha, G.Mahesh, N.Muthuprakash, "Optimization of CNC Turning Process Parameters on ALUMINIUM 6061 Using Genetic Algorithmnternational 
Journal of Science and Modern Engineering (IJISME) ISSN:

2319-6386, Volume-1, Issue-9, August 2013.

[9]. Y.B. Kumbhar, C.A. Waghmare, "Tool life and surface roughness optimization of PVD TiAlN/TiN multilayer coated carbide inserts in semi hard turning of hardened EN31 alloy steel under dry cutting conditions", International Journal of Advanced Engineering Research and Studies EISSN2249-8974. 